\title{
Vaccinia Virus-Based Reverse Genetics for Feline Coronaviruses
}

\section{Gergely Tekes}

\begin{abstract}
For decades, the genetic modification of coronavirus genomes and the generation of recombinant coronaviruses have been hampered mostly due to the extraordinary large size of the coronaviral genome. The very first reverse genetic system for feline coronaviruses (FCoVs) was established in the early 2000s; the respective approach exclusively enabled the manipulation of the $3^{\prime}$-third of the viral genome. Later on, vaccinia virus- and bacterial artificial chromosome (BAC)-based systems have been developed. Both systems have the advantage that the entire FCoV genome is amenable for mutagenesis. The main focus of this chapter is the vaccinia virus-based reverse genetic system for FCoVs. Here we present protocols for ( 1 ) the generation of a full-length cDNA clone, (2) the manipulation of the FCoV genome, and (3) the rescue of recombinant FCoVs.
\end{abstract}

Key words Coronavirus, Feline coronavirus (FCoV), Reverse genetics, Infectious clone, Recombinant FCoVs, Vaccinia virus, Homologous recombination, GPT positive selection, GPT negative selection

\section{Introduction}

The establishment of a reverse genetic system for feline coronaviruses (FCoVs), which allows to modify the entire coronaviral genome, was successfully achieved for the first time in 2008 [1]. This system relies on vaccinia virus, which serves as a cloning vector for the full-length FCoV cDNA. The very first vaccinia virusbased reverse genetic system was developed for the human coronavirus (HCoV) $229 \mathrm{E}$ [2] and since then it has been successfully applied for other coronaviruses, e.g., infectious bronchitis virus (IBV) [3] or mouse hepatitis virus (MHV) [4]. The major advantage of the vaccinia virus-based reverse genetic system lies in the stable integration of full-length corona viral cDNAs into the vaccinia virus genome. In contrast, other conventional cloning techniques often are not suitable for the accommodation of large coronaviral cDNA inserts due to instability of the plasmids caused by certain coronaviral sequences. However, reverse genetic systems, 
which are based on different techniques other than vaccinia virus, have been developed and used successfully for the generation of various recombinant coronaviruses [5-11].

Here, the vaccinia virus-based FCoV reverse genetic system is described. In the first part of this chapter, different strategies for the assembly of the full-length $\mathrm{FCoV}$ cDNA and its integration into the vaccinia virus genome are presented (Sect. 3.1). Second, the manipulation of the FCoV cDNA integrated into the vaccinia virus genome is outlined (Sect. 3.2), followed by the recovery of recombinant feline coronaviruses (Sect. 3.3).

\section{Materials}

\subsection{Required}

for Sect. 3.1
2.2 Required

for Sect. 3.2
1. Cloning and ligation.

- pGemT TA cloning kit (Promega).

- High-concentrated T4 DNA ligase (Fermentas).

- Antarctic phosphatase (NEB).

- Qiaex II gel extraction kit (Qiagen).

- CHEF Mapper-II pulse-field gel electrophoresis System (Bio-Rad).

- Vaccinia Virus vNotI/tk [12], fowl-pox virus.

2. Vaccinia virus large-scale DNA preparation.

- BHK-2l cells.

- DMEM cell culture medium (Sigma).

- $\quad 10 \times$ buffer A (10 mM Tris-HCl pH 9.0, 1 mM EDTA).

- MagNaLyser Green Beads (Roche).

- MagNaLyser Instrument (Roche).

- Beckman ultracentrifuge with rotor SW28.

- Trypsin.

- RNase-free DNase with the appropriate 10× buffer (Promega).

- Proteinase K (Roche).

- $\quad 2 \times$ proteinase K buffer $(200 \mathrm{mM}$ Tris-HCl pH 7.5, $10 \mathrm{mM}$ EDTA pH 8.0, 0.5 \% SDS, $400 \mathrm{mM} \mathrm{NaCl}$ ).

- RNase-free water.

1. DMEM cell culture medium (Sigma).

2. CV-1 cells [13].

3. D980R cells [13]. 
4. Lipofectamine 2000 (Life Technologies).

5. Sonication water bath.

6. Selective medium for GPT positive selection: (1) xanthine (Sigma) $10 \mathrm{mg} / \mathrm{ml}$ in $0.1 \mathrm{M} \mathrm{NaOH}$; (2) hypoxanthine (Sigma) $10 \mathrm{mg} / \mathrm{ml}$ in $0.1 \mathrm{M} \mathrm{NaOH}$; (3) mycophenolic acid (MPA) (Sigma). For an entire 6-well plate use $12 \mathrm{ml}$ of medium and supplement it with $300 \mu \mathrm{l}$ xanthine, $18 \mu \mathrm{l}$ hypoxanthine, and $30 \mu \mathrm{l}$ MPA from the above described stocks.

7. Selective medium for GPT negative selection: 6-thioguanine (6-TG) (Sigma) $1 \mathrm{mg} / \mathrm{ml}$ in $0.1 \mathrm{M} \mathrm{NaOH}$. For an entire 6-well plate use $12 \mathrm{ml}$ of medium and supplement it with $12 \mu \mathrm{l}$ 6-TG from the above described stock.

\subsection{Required} for Sect. 3.3

2.3.1 In Vitro RNA Synthesis

2.3.2 Electroporation
1. RiboMax large-scale RNA production system-T7 (Promega).

2. Cap analog $30 \mathrm{mM}$ (7mGpppG) (NEB).

3. RNase inhibitor (Promega).

4. RNase-free DNase (Promega).

5. LiCl solution (7.5 M LiCl, $50 \mathrm{mM}$ EDTA pH 7.5).

6. RNase-free water.

1. Crfk-TetOn-N cells (generated in our laboratory).

2. $1 \times$ phosphate-buffered saline (PBS).

3. Electroporator (Bio-Rad Gene Pulser).

4. Electroporation cuvette (4 mm gap) (VWR).

\section{Methods}

\subsection{Integration of the Full-Length FCoV cDNA into the Vaccinia Virus Genome}

Two alternative strategies for the assembly of the full-length FCoV infectious clone are described. The first strategy represents a twostep approach (Sect. 3.1.1).This method involves (1) the introduction of the major part of the $\mathrm{FCoV}$ genome through in vitro ligation into the vaccinia virus genome (section "Integration of the FCoV cDNA into the Vaccinia Virus Genome via In Vitro Ligation") followed by (2) the completion of the full-length FCoV cDNA via vaccinia virus-mediated homologous recombination (section "Second Step"). The reason for this strategy is that certain coronavirus-derived sequences can cause instability in cloning plasmids, which makes it difficult to assemble the full-length FCoV cDNA by in vitro ligation of $\mathrm{FCoV} \mathrm{cDNA}$ fragments originating from plasmids. Such an approach was applied for the establishment of the first FCoV infectious clone [1]. Since then, this infectious clone has been successfully applied to study different aspects of FCoV biology [14-16]. In Sect. 3.1.2 an alternative strategy is 


\subsubsection{Two-Step Strategy for the Introduction of the Complete FCoV cDNA into the Vaccinia Virus Genome}

First Step

Generation of Plasmids Suitable for the In Vitro Ligation described, which simplifies the procedure for the generation of the FCoV infectious clone (Tekes, unpublished). This approach omits all of the in vitro ligation steps and it is based exclusively on vaccinia virus-mediated homologous recombination. Regardless of the applied strategy, viral RNA serves as a starting material for the generation of all FCoV-sequence containing plasmids (sections "First Step", 3.1.1.3, "Generation of plasmids suitable for vaccinia virus-mediated homologous recombination").

1. Coronavirus-derived sequences, which can cause instability in cloning vectors, are often located between nt 5000 and 15,000 of the coronaviral genomic sequence. Therefore, this part of the genome should be introduced into the vaccinia virus genome by vaccinia virus-mediated homologous recombination in the second step as described in section "Completion of the FCoV cDNA Using Vaccinia Virus-Mediated Homologous Recombination".

2. Analyze the remaining parts of the FCoV sequence $(1-5000$ and 15,000-29,000 nt) and choose restriction enzyme sites encoded by the FCoV genome that will allow the in vitro ligation of cloned cDNA inserts. After the analysis, prepare a set of plasmids (no more than 4-5) covering the FCoV genome from nt 1 to 5000 and from nt 15,000 to 29,000 (Fig. la).

3. Plasmid A ( $\mathrm{pA})$ contains upstream of the FCoV sequence a Bsp120I site followed by a T7 promoter and a G nucleotide. The Bsp120I site is required for the ligation of the cDNA insert derived from $\mathrm{pA}$ with the NotI digested vaccinia virus DNA (section "Large-Scale Vaccinia Virus DNA Preparation").The T7 promoter for the T7 RNA polymerase enables the generation of full-length FCoV RNA via in vitro transcription (IVT) (Sect. 3.3.1). The presence of the $\mathrm{G}$ nucleotide is recommended for the proper initiation of the T7 polymerase. Furthermore, plasmid D ( $\mathrm{pD}$ ) should contain downstream of the FCoV 3'UTR 20-30 A nucleotides, which will serve as a synthetic poly-A tail after IVT. These A nucleotides should be followed by a unique cleavage site (e.g., ClaI), the hepatitis delta ribozyme (HDR) sequence, and a Bsp120I cleavage site (Fig. la). The digestion of the vaccinia virus DNA with the unique restriction enzyme will enable to terminate the T7 polymerase driven RNA synthesis (Sect. 3.3.1). The HDR sequence fulfills the same function and contributes to the termination of the FCoV RNA. The Bsp120I enables the in vitro ligation of the cDNA insert originating from pDinto the NotI cleaved vaccinia virus DNA (section "Large-Scale Vaccinia Virus DNA Preparation"). 


\section{a}
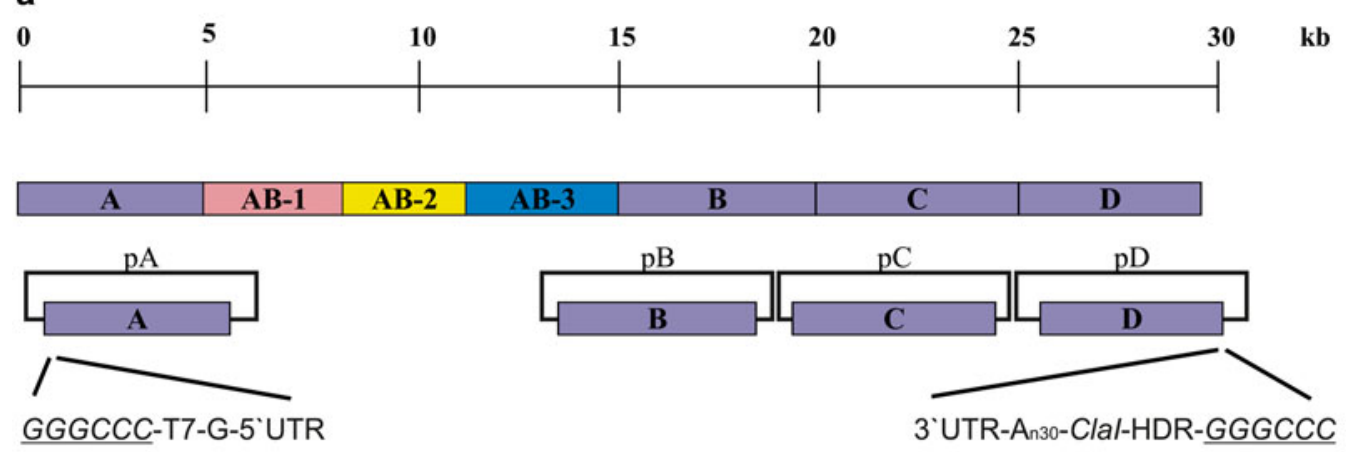

b

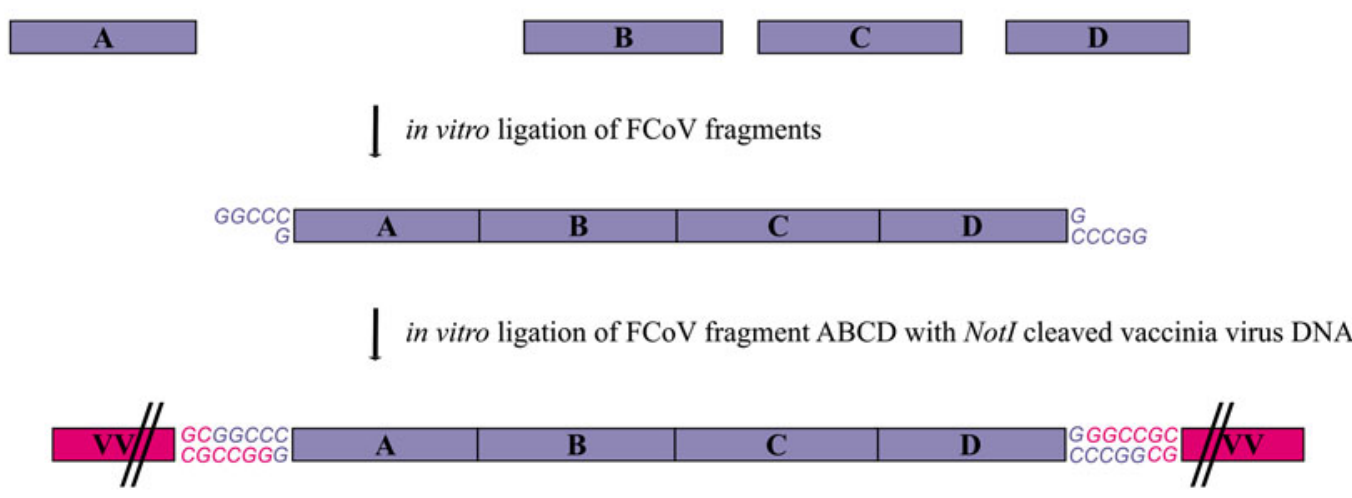

Fig. 1 Schematic representation of the strategy to introduce approximately two-thirds of the FCoV cDNA into the vaccinia virus genome. (a) The nearly $30 \mathrm{~kb}$ long FCoV genome, which is divided into seven parts $(A, A B-1$, $A B-2, A B-3, B, C$, and $D)$, is depicted. Plasmids $A, B, C$, and $D(p A, p B, p C$, and $p D)$ are shown. The detailed descriptions of the 5 'end of fragment $A$ and the $3^{\prime}$ end of fragment $D$ in $p A$ and $p D$ are shown, respectively. In pA the FCoV sequence is preceded by a Bsp120l recognition site (underlined), T7 DNA-dependent RNA polymerase promoter (T7), and a G nucleotide. In pD the FCoV sequence is followed by poly-A sequence $\left(A_{n 30}\right)$, Clal cleavage site, hepatitis delta ribozyme (HDR) sequence, and a Bsp120l recognition site (underlined). (b) Fragments $\mathrm{A}, \mathrm{B}, \mathrm{C}$, and $\mathrm{D}$ (purple boxes) derived from plasmids $\mathrm{pA}, \mathrm{pB}, \mathrm{pC}$, and $\mathrm{pD}$ are ligated to obtain fragment $A B C D$. The overhangs of the Bsp120l recognition sites, which enable the ligation into the Notl cleaved vaccinia virus $D N A$, are shown in purple. In a further step, fragment $A B C D$ is ligated into the vaccinia virus (VV) genome (pink boxes). The overhangs originating from the Notl cleavage site in the vaccinia virus DNA and the Bsp120l sites from fragment $A B C D$ are depicted in pink and purple, respectively

In Vitro Ligation of FCoV cDNA Inserts
1. Digest approximately $100 \mu \mathrm{g}$ of each plasmid with the appropriate restriction enzymes resulting in cDNA fragments A, B, $\mathrm{C}$, and D. In order to avoid the ligation of fragments A and D together through the Bsp120I site during the in vitro ligation process (section "In vitro Ligation of FCoV cDNA Inserts"), treat these fragments with alkaline phosphatase. Isolate the fragments using standard gel extraction kit (see Note $\mathbf{1}$ ).

2. Set up an in vitro ligation reaction (total volume $20-30 \mu \mathrm{l}$ ) with all of the fragments in the presence of a high-concentrated T4 DNA ligase overnight at room temperature. 
Large-Scale Vaccinia Virus DNA Preparation
3. Analyze the efficiency of your ligation on an agarose gel after heating up the samples for $5-10 \mathrm{~min}$ at $65^{\circ} \mathrm{C}$. If the result of the ligation is not satisfying, repeat the small-scale ligation with different ratios of the fragments. If the desired ligation product can be observed, proceed to the next step.

4. Use the same conditions as in step 3 for a large-scale ligation. Load the entire reaction on agarose gel and purify the desired ligation product using a gel extraction kit, which enables the efficient recovery of cDNAs larger than $15 \mathrm{~kb}$. For the excision of the band avoid the use of UV-light (see Note 1). Use this purified product for the ligation with the NotI digested vaccinia virus DNA in order to integrate the $\mathrm{FCoV}$ cDNA into the vaccinia virus genome (section "Integration of the FCoV cDNA into the Vaccinia Virus Genome via In Vitro Ligation") (Fig. 1b).

For the following experiment the vaccinia virus strain $v N o t I / t k$ is used. This vaccinia virus genome contains only a single NotI cleavage site, which enables the introduction of the FCoV cDNA into the vaccinia virus genome via in vitro ligation.

1. Infect four T150 cell culture flasks/dishes of BHK-21 cells (90\% confluent) with vaccinia virus. Harvest the fully infected cells 2-3 days post infection.

2. Pellet the cells at $2000 \mathrm{RPM}\left(4^{\circ} \mathrm{C}, 3 \mathrm{~min}\right)$.

3 . Resuspend the cell pellet in $3 \mathrm{ml}$ of chilled $1 \times$ buffer $A$ and fill three MagNaLyser Green Beads with $1 \mathrm{ml}$ suspension each.

4. Homogenize the cells with the MagNaLyser Instrument (Roche) at 5000 RPM for $20 \mathrm{~s}$.

5. Spin the beads for $1-2 \mathrm{~min}$ at $2000 \mathrm{RPM}\left(4^{\circ} \mathrm{C}\right)$.

6. Collect the supernatant from the three tubes and combine it into a new tube.

7. Digest the content of the new tube with RNase-free DNase (5U) for $20 \mathrm{~min}$ at $37^{\circ} \mathrm{C}$ to degrade the remaining cellular DNA in the reaction. Supplement the reaction with the appropriate buffer $(10 \times$ DNase buffer $)$. Within the virions the vaccinia virus DNA is protected from this digestion step.

8. Inactivate the DNase by adding $20 \mathrm{mM}$ EDTA and incubate the reaction for $20 \mathrm{~min}$ at $65^{\circ} \mathrm{C}$.

9. Proceed with trypsin digestion as follows: 0.1 volume of $0.25 \%$ $(\mathrm{w} / \mathrm{v})$ trypsin for $20 \mathrm{~min}$ at $37^{\circ} \mathrm{C}$.

10. Fill up the reaction volume to $11 \mathrm{ml}$ with chilled $1 \times$ buffer $A$ and overlay it on $25 \mathrm{ml} 36 \%(\mathrm{w} / \mathrm{v})$ sucrose cushion in a $36 \mathrm{ml}$ ultracentrifuge tube. Spin it down for $80 \mathrm{~min}$ at 13,500 RPM at $4{ }^{\circ} \mathrm{C}$ using a SW 28 rotor.

11. Discard the supernatant and resuspend the pellet in $400 \mu \mathrm{l}$ buffer A. 
12. Add the same volume of $2 \times$ proteinase $\mathrm{K}$ buffer and 4-5 $\mu \mathrm{l}$ proteinase $\mathrm{K}$ to the reaction and incubate for $2 \mathrm{~h}$ at $55^{\circ} \mathrm{C}$.

13. After the incubation, pipet $400 \mu \mathrm{l}$ in two fresh Eppendorf tubes for DNA extraction using phenol-chloroform. Perform the same steps with both reaction tubes (see Note 2).

14. Add $400 \mu \mathrm{l}$ of chilled phenol to the reaction, mix it gently (see Note 3 ) and spin down using a table centrifuge $(5 \mathrm{~min}$, 13,000 RPM at $4{ }^{\circ} \mathrm{C}$ ). Pipet the water phase into a fresh tube and add $400 \mu \mathrm{l}$ of chilled chloroform. Mix gently and spin again ( 5 min, 13,000 RPM at $4{ }^{\circ} \mathrm{C}$ ).

15. Pipet the water phase into a fresh tube and add $1 \mathrm{ml}$ of $(2.5$ volume) chilled $100 \%$ ethanol to it. Mix carefully and spin down $\left(5 \mathrm{~min}, 13,000 \mathrm{RPM}\right.$ at $\left.4{ }^{\circ} \mathrm{C}\right)($ see Note 2$)$.

16. Discard the supernatant and wash the DNA pellet with 500-800 $\mu 170 \%$ ethanol. Spin it down (5 min, 13,000 RPM at $\left.4{ }^{\circ} \mathrm{C}\right)$.

17. Optional: repeat step 16 to increase the purity of the DNA.

18. Discard the supernatant and add $25 \mu \mathrm{l}$ of RNase-free water (see Note 4).

19. Combine the DNA from both tubes and use everything for the in vitro ligation ( see Note 2). (section "Integration of the FCoV cDNA into the Vaccinia Virus Genome via In Vitro Ligation”).

Integration of the FCoV cDNA into the Vaccinia Virus Genome via In Vitro Ligation
1. Digest the entire amount of the vaccinia virus DNA (from section "Large-Scale Vaccinia Virus DNA Preparation", step 19) with NotI enzyme for $3-4$ h at $37^{\circ} \mathrm{C}$.

2. Add all of the ligated FCoV cDNA insert (from section "In Vitro Ligation of FCoV cDNA Inserts", step 4) to the cleaved vaccinia virus DNA and incubate overnight at room temperature in the presence of a high-concentrated DNA ligase and NotI restriction enzyme. Supplement the reaction with the appropriate buffers (10× ligation buffer and $10 \times$ NotI buffer). The volume of the ligation reaction can reach up to 100$150 \mu \mathrm{l}$. If necessary, pipet additional NotI and/or DNA ligase to the reaction. The presence of NotI enzyme prevents the relegation of the vaccinia virus DNA ends.

3. Next day, examine the efficiency of your ligation using pulse field gel electrophoresis (PFGE). Load no more than 5-10 $\mu \mathrm{l}$ aliquot on the gel after heating up the samples for 5-10 min at $65{ }^{\circ} \mathrm{C}$. Freeze the rest of the ligation reaction at $-20{ }^{\circ} \mathrm{C}$ and use the DNA later for the recovery of vaccinia virus containing the FCoV cDNA (section "Recovery of FCoV cDNA-Containing Vaccinia Virus").

4. If the result of the PFGE is satisfying, proceed with the recovery (see Note 5). 
Recovery of FCoV cDNA-Containing Vaccinia Virus

Second Step

Generation of Plasmids

Suitable for Vaccinia

Virus-Mediated

Homologous

Recombination
1. Infect almost confluent $(90 \%) \mathrm{CV}-1$ cells in one well of a 6-well plate with the fowl-pox virus at an MOI of 5 for $2 \mathrm{~h}$ (see Note 6).

2. Transfect the entire in vitro ligated vaccinia virus DNA (section "Integration of the FCoV cDNA into the Vaccinia Virus Genome via In Vitro Ligation") without further purification using Lipofectamine 2000 ( see Note 2).

3. 5-6 h post transfection: discard the cell culture supernatant, trypsinize, and pellet the cells.

4. Supplement the transfected cells with fresh CV-1 cells $\left(4 \times 10^{6}\right)$ and seed them on a 96-well plate.

5. Incubate the plate at $37^{\circ} \mathrm{C}$ until complete cytopathic effect (CPE) develops (5-10 days) in some of the wells.

6. Harvest the cells with CPE and infect fresh CV-1 cells in a well of a 6-well plate with half of the harvested material.

7. Incubate the CV-1 cells until complete CPE develops. Harvest the cells and divide it into two equal aliquots.

8. Take one of the aliquots, pellet the cells and perform vaccinia virus DNA preparation using proteinase $\mathrm{K}$ digestion followed by phenol-chloroform extraction as described (section "LargeScale Vaccinia Virus DNA Preparation", steps 12-18).

9. Analyze the presence of the $\mathrm{FCoV}$ sequence in the vaccinia virus genome by PCR.

10. If the FCoV sequence was successfully integrated into the vaccinia virus genome, proceed with the second step (section "Generation of Plasmids Suitable for Vaccinia Virus-Mediated Homologous Recombination"). The resulting recombinant vaccinia virus is called vrecFCoV-ABCD.

In order to achieve the integration of the full-length FCoV cDNA into the vaccinia virus genome, the remaining part of the $\mathrm{FCoV}$ genome (nt 5000-15,000) is introduced by vaccinia virus-mediated homologous recombination.

1. Generate DNA fragments $\mathrm{AB} 1, \mathrm{AB} 2$, and $\mathrm{AB} 3$ by RT-PCR. Clone fragments $\mathrm{ABl}$ and $\mathrm{AB} 3$ corresponding approximately to the FCoV sequence nt 4500-8500 and $115,000-15,500$, respectively, upstream and downstream of the phosphoribosyltransferase (GPT) gene in the plasmid pGPT-1 [13] in order to generate pGPT-AB-1/3 (Fig. 2a). The fragment AB-1 contains a $500 \mathrm{nt}$ long overlapping piece at its $5^{\prime}$ terminal with fragment A. Fragment AB-3 possesses a $500 \mathrm{nt}$ long overlapping piece at its $3^{\prime}$ terminal with fragment $\mathrm{B}$. These overlapping sequences are required for the vaccinia virus-mediated homologous recombination. Clone fragment AB2 corresponding approximately to the 

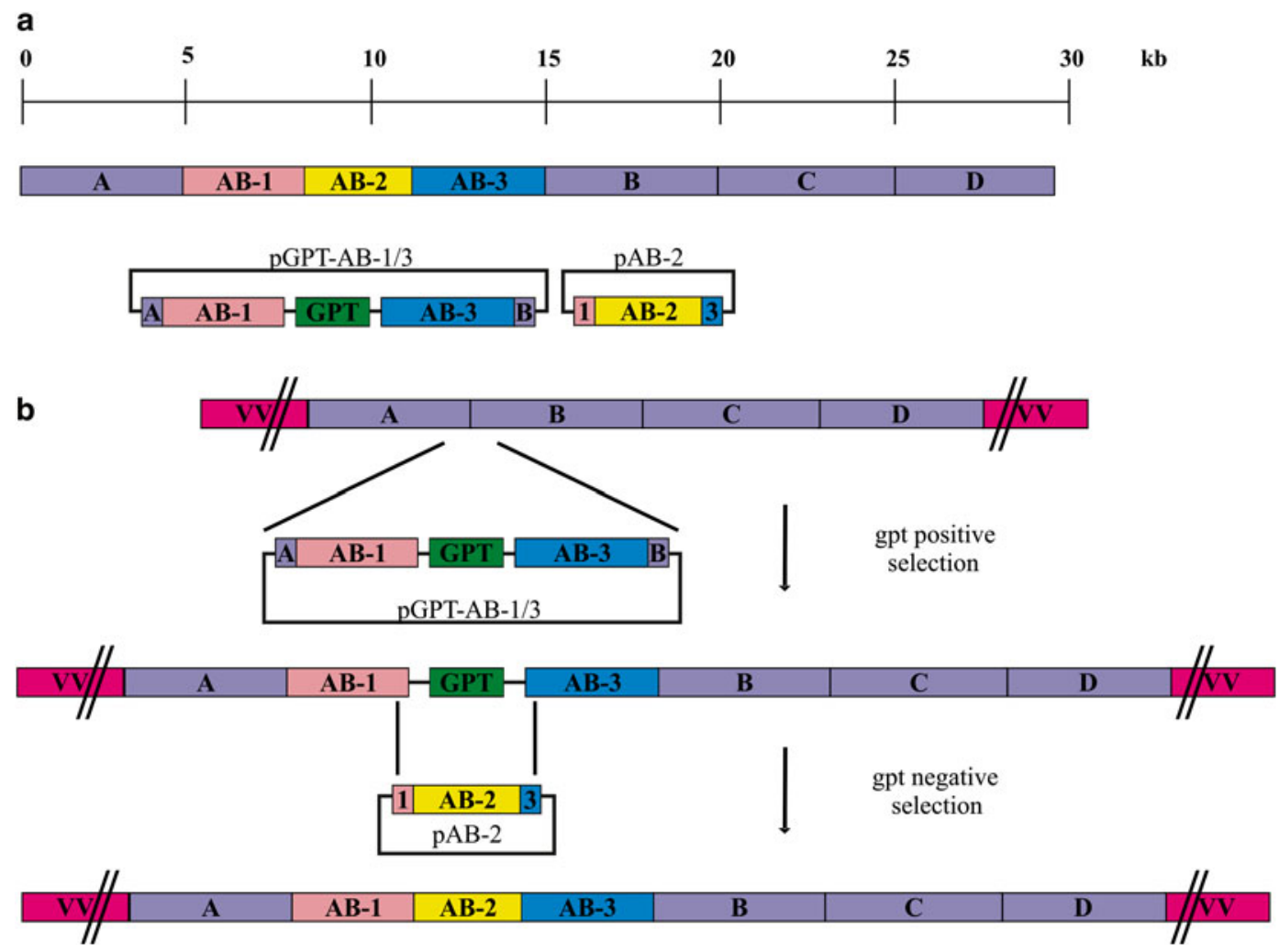

Fig. 2 Completion of the FCoV infectious clone. In order to complete the full-length FCoV cDNA, fragments $A B-1,-2$, and -3 are introduced using two rounds of vaccinia virus-mediated homologous recombination with GPT positive and GPT negative selection using the plasmids pGPT-AB-1/3 and pAB-2. GPT guanine phosphoribosyl transferase

Completion of the FCoV cDNA Using Vaccinia Virus-Mediated Homologous Recombination

3.1.2 Alternative Strategy to Generate a Full-Length FCoV Clone Omitting the In Vitro Ligation
FCoV sequence nt $8000-1200$ into a suitable plasmid backbone (Fig. 2a). This fragment contains at both ends $500 \mathrm{nt}$ long overlapping fragments with $\mathrm{AB}-1$ and $\mathrm{AB}-3$, respectively. The overlapping sequences are prerequisites for the vaccinia virus-mediated homologous recombination. The required cleavage sites of $\mathrm{ABl}$, $\mathrm{AB} 2$, and $\mathrm{AB} 3$ for the cloning reactions must be included through the primer sequences designed for the RT-PCR.

The missing part of the FCoV genome (nt 5000-15,000) is introduced by two rounds of vaccinia virus-mediated homologous recombination using GPT as a positive and negative selection marker. The overall strategy is presented in Fig. 2b; the technical details are described in Sect. 3.2.

If no cloning difficulties are observed with large (4-5 kb) fragments covering the entire FCoV genome, the use of the following method is recommended. One major advantage of this approach is that the time consuming and complicated in vitro ligation steps 
Generation of Plasmids

Suitable for Vaccinia

Virus-Mediated

Homologous

Recombination

(sections "In vitro Ligation of FCoV cDNA Inserts" and "Integration of the FCoV cDNA into the Vaccinia Virus Genome via In Vitro Ligation") can be avoided. However, depending on the success of the cloning process, both approaches (Sects. 3.1.1 and 3.1.2) present suitable tools to build an FCoV infectious clone. This alternative strategy involves the introduction of the full-length FCoV cDNA into the vaccinia virus genome using exclusively vaccinia virus-mediated homologous recombination.

1. Divide the FCoV genome into eight segments. Accordingly, prepare eight fragments by RT-PCR with a size of 3.5-4 kb each covering the entire FCoV genome (Fig. 3).Clone these RT-PCR fragments into a commercial available TA cloning vector in order to generate plasmids $1-8(\mathrm{pl}, \mathrm{p} 2, \mathrm{p} 3, \mathrm{p} 4, \mathrm{p} 5$, p6, p7, and p8).

2. Plasmid $\mathrm{l}(\mathrm{pl})$ contains upstream of the FCoV sequence a $500 \mathrm{nt}$ long piece of the vaccinia virus genome followed by a T7

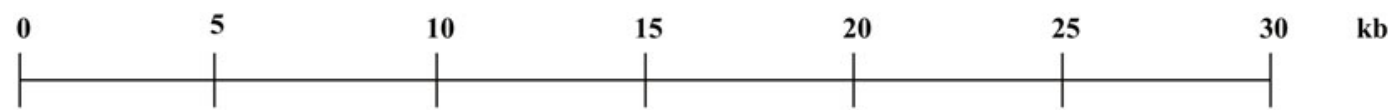

\begin{tabular}{|l|l|l|l|l|l|l|l|}
\hline $\mathbf{1}$ & 2 & 3 & 4 & 5 & 6 & 7 & 8 \\
\hline
\end{tabular}
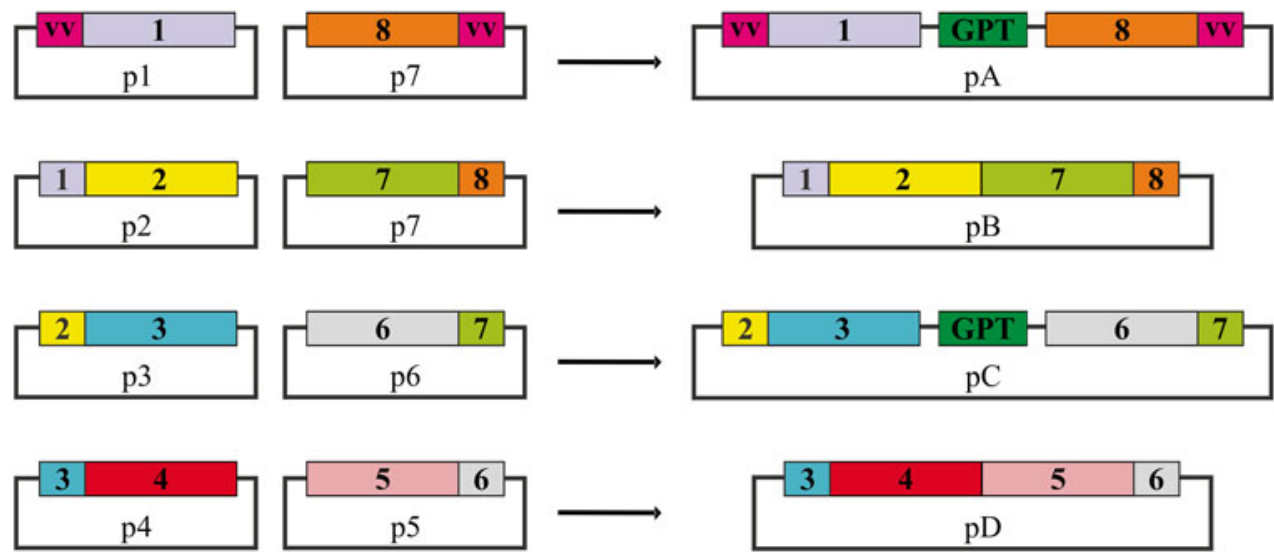

Fig. 3 Generation of plasmids required for the introduction of the full-length FCoV genome into the vaccinia virus genome by vaccinia virus-mediated homologous recombination. For the assembly of the cDNA clone, the approximately $30 \mathrm{~kb}$ long FCoV genome is divided into eight overlapping fragments (1-8). The fragments are color-coded. Eight plasmids (p1, p2, p3, p4, p5, p6, p7, and p8) corresponding to these fragments are depicted. Out of these eight plasmids, the generation of four final plasmids ( $\mathrm{pA}, \mathrm{pB}, \mathrm{pC}$, and $\mathrm{pD}$ ), which are required for the introduction of the entire FCoV cDNA into the vaccinia virus (VV) genome, are shown. The overlapping parts of the various fragments are required for the vaccinia virus-mediated homologous recombination. GPT guanosine phosphoribosyl transferase 
promoter and a G nucleotide. Plasmid 8 (p8) corresponds to the $3^{\prime}$ end of the FCoV genome sequence followed by 20-30 A nucleotides (synthetic poly-A tail), a unique cleavage site, the hepatitis delta ribozyme (HDR) sequence and a $500 \mathrm{nt}$ long piece of the vaccinia virus genome. Plasmid 2 (p2) contains an approximately $500 \mathrm{nt}$ long overlapping part with pl. Plasmid 7 (p7) has an approximately $500 \mathrm{nt}$ long overlapping part with p8. Plasmid 3 (p3) has an approximately $500 \mathrm{nt}$ long overlapping part with p2. Plasmid 6 (p6) contains an approximately $500 \mathrm{nt}$ long overlapping part with p7. Plasmid $4(\mathrm{p} 4)$ has an approximately $500 \mathrm{nt}$ long overlapping part with p3. Plasmid 5 (p5) comprises an approximately $500 \mathrm{nt}$ long overlapping part with p6. These overlapping parts are required for the vaccinia virusmediated homologous recombination. In order to finalize the plasmids needed for the vaccinia virus-mediated homologous recombination, additional cloning steps are required (steps 3-6).

3. Clone fragments $\mathrm{l}$ and 8 originating from $\mathrm{pl}$ and $\mathrm{p} 8$, respectively, upstream and downstream of the GPT gene in the multiple cloning sites of the pGPT- 1 . The specific restriction enzyme cleavage sites required for the subcloning originate from the primer sequences used for the generation of the RTPCR products. The resulting plasmid is called plasmid A (pA) (Fig. 3).

4. Clone fragment 2 originating from $\mathrm{p} 2$ in the $\mathrm{p} 7$ in order to obtain plasmid $\mathrm{B}(\mathrm{pB})$. The specific restriction enzyme cleavage sites required for the subcloning originate from the primer sequences used for the generation of the RT-PCR products.

5. Clone fragments 3 and 6 originating from $\mathrm{p} 3$ and $\mathrm{p} 6$, respectively, upstream and downstream of the GPT gene in the pGPT- 1 . The specific restriction enzyme cleavage sites required for the subcloning originate from the primer sequences used for the generation of the RT-PCR products. The resulting plasmid is called plasmid $\mathrm{C}(\mathrm{pC})$.

6. Clone fragment 4 originating from $\mathrm{p} 4$ in the $\mathrm{p} 5$ in order to obtain plasmid $\mathrm{D}(\mathrm{pD})$. The cleavage site between fragments 4 and 5 is present in the original $\mathrm{FCoV}$ sequence. The other restriction enzyme cleavage sites required for the subcloning originate from the primer sequences used for the generation of the RT-PCR products.

Introduction of the FullLength $\mathrm{FCoV}$ cDNA by Vaccinia Virus-Mediated Homologous Recombination
The entire FCoV genome is introduced by four rounds of vaccinia virus-mediated homologous recombination using GPT as a positive and negative selection marker. The overall strategy is presented in Fig. 4; the technical details are described in Sect. 3.2. 


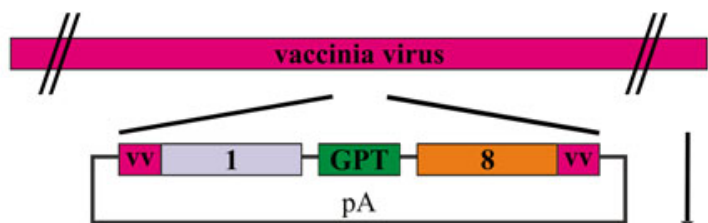

1. gpt positive selection

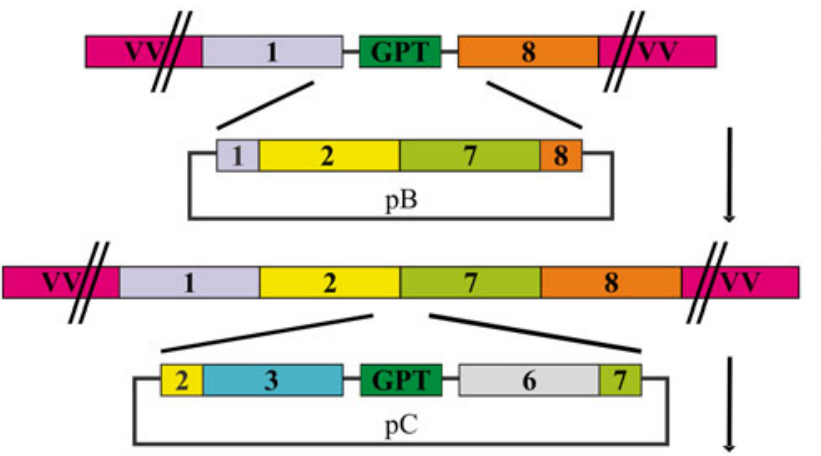

1. gpt negative selection

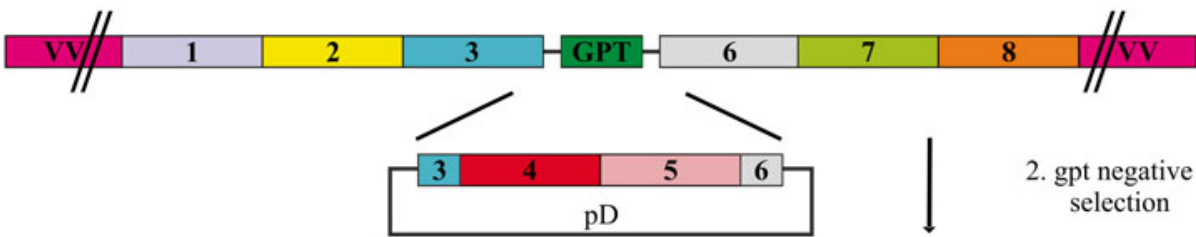

\begin{tabular}{|l|l|l|l|l|l|l|l|l|l|}
\hline VV// & $\mathbf{1}$ & $\mathbf{2}$ & $\mathbf{3}$ & 4 & 5 & 6 & 7 & 8 & $\mathbf{8}$ \\
\hline
\end{tabular}

Fig. 4 Strategy for introduction of the full-length FCoV cDNA into the vaccinia virus genome by vaccinia virusmediated homologous recombination. In order to integrate the full-length FCoV cDNA, fragments 1-8 are introduced via four rounds of vaccinia virus-mediated homologous recombination using GPT as a positive and a negative selection marker. The required plasmids $(\mathrm{pA}, \mathrm{pB}, \mathrm{pC}$, and $\mathrm{pD})$ and the resulting recombinant vaccinia viruses are shown. GPT guanine phosphoribosyl transferase

\subsection{Manipulation} of the FCoV Genome Vaccinia VirusMediated Homologous Recombination
For the manipulation of the FCoV sequence integrated in the vaccinia virus genome, specifically designed plasmids in combination with vaccinia virus-mediated homologous recombination are required. This approach allows the replacement of defined parts of the $\mathrm{FCoV}$ genome.

In an initial step, the GPT gene is introduced into the vaccinia virus genome. For this purpose a specific plasmid is required, which contains upstream and downstream of the GPT gene homologous sequences $(500 \mathrm{nt})$ with the targeted FCoV region. These homologous sequences in the plasmid enable the insertion of the GPT gene (preceded by a vaccinia virus promoter) by vaccinia virus-mediated double homologous recombination in the vaccinia virus genome. The resulting recombinant vaccinia virus with GPT gene can be selected using the GPT as a positive selection marker (Sect. 3.2.2).

In the following step, the GPT gene is replaced by the FCoV sequence with the desired mutations. The required specific plasmid 
3.2.1 Infection and Transfection
3.2.2 GPT Positive Selection contains two homologous regions (500 nt) with the targeted FCoV sequence upstream and downstream of the FCoV sequence to be introduced. Vaccinia virus-mediated homologous recombination leads to replacement of the GPT gene by the FCoV sequence with the desired mutations. In the absence of the GPT gene, the resulting recombinant vaccinia virus can be selected using GPT as a negative selection marker (Sect. 3.2.3).

In order to generate the GPT positive/negative recombinant vaccinia viruses, cells are infected with the appropriate vaccinia virus and transfected with the specifically designed plasmids. During incubation of infected/transfected cells vaccinia virus-mediated homologous recombination takes place between the homologous sequences of the vaccinia genome and the plasmid sequence.

1. Infect CV-1 cells (90\% confluent) in one well of a six-well plate with vaccinia virus $(\mathrm{MOI}=1)$. Incubate the reaction for $2 \mathrm{~h}$ at $37^{\circ} \mathrm{C}$.

2. 2 h post infection: transfect the cells with $2-4 \mu \mathrm{g}$ of the specific plasmid designed for the mutagenesis using Lipofectamine 2000. The transfection is carried out according to the manufacturer's instruction.

3. 5-6 h post transfection: wash the cells and cover them with fresh medium $(2 \mathrm{ml})$.

4. Incubate the infected/transfected cells until complete CPE develops $(48-72 \mathrm{~h})$.

5. Harvest the cells by scratching, resuspend in $800 \mu$ l of supernatant, and store at $-20{ }^{\circ} \mathrm{C}$.

6. This material contains the newly generated GPT positive vs. negative recombinant vaccinia viruses, which will be selected using GPT as positive (Sect. 3.2.2) or negative (Sect. 3.2.3.) selection marker in a following step.

1. Seed CV-1 cells in a six-well plate 1 day before positive selection starts. On the day of selection the cells should be approximately $90 \%$ confluent.

2. On the next morning, supplement the medium with $25 \mu \mathrm{g} / \mathrm{ml}$ mycophenolic acid (MPA), $250 \mu \mathrm{g} / \mathrm{ml}$ xanthine, and $15 \mu \mathrm{g} /$ $\mathrm{ml}$ hypoxanthine. Incubate the cells for at least $6 \mathrm{~h}$ with the GPT positive selection medium.

3. Prepare the vaccinia virus for infection (from Sect. 3.2.1, step 5 ): freeze and thaw the virus three times by placing it into liquid nitrogen followed by sonication $(5 \mathrm{~min})$. This step is necessary to release and separate the vaccinia virus particles from the cells.

4. Use $10 \mu \mathrm{l}$ of different dilutions (stock, $1: 10$, and $1: 100$ ) of this virus for the infection of the CV-1 cells. 
3.2.3 GPT Negative Selection

\subsection{Recovery of Recombinant FCoVs}

5. Incubate the infected cells until single plaques develop (48 h post infection).

6. Pick the plaques (usually six) in $150 \mu \mathrm{l}$ medium and use $10 \mu \mathrm{l}$ for the infection of fresh CV-1 cells treated with GPT positive selection medium.

7. Prior infection freeze and thaw the virus as described in step 3 .

8. Repeat the selection step 3-4 times.

9. After the last round of selection, infect CV-1 cells in a well of a 6-well plate with 30-40 $\mu$ l plaque material. Incubate the cells until complete CPE develops (2-4 days). Harvest the cells and divide them into two Eppendorf tubes. One tube should be stored at $-20{ }^{\circ} \mathrm{C}$, which can be used later for the GPT negative selection (Sect. 3.2.3). Prepare vaccinia virus DNA from the other half of the reaction to verify the result of the recombination event by PCR.

1. Seed D980R cells in a six-well plate 1 day before negative selection starts. On the day of selection the cells should be $40 \%$ confluent.

2. On the next morning, supplement the medium with $1 \mu \mathrm{g} / \mathrm{ml}$ 6-thioguanine (6-TG). Incubate the cells at least for $6 \mathrm{~h}$ with the GPT negative selection medium.

3. Prepare the vaccinia virus for infection (from Sect. 3.2.2, step 9 ): freeze and thaw the virus three times by placing it into liquid nitrogen followed by sonication ( $5 \mathrm{~min}$ ).

4. Use $10 \mu \mathrm{l}$ of different dilutions (stock, $1: 10$, and 1:100) of this virus for the infection of the D980R cells.

5. Incubate the infected cells until single plaques develop (48 h post infection).

6. Pick the plaques (usually six) in $150 \mu \mathrm{l}$ medium and use $10 \mu \mathrm{l}$ for the infection of fresh D980R cells treated with GPT negative selection medium.

7. Prior infection freeze and thaw the virus as described in step 3 .

8. Repeat the selection step 3-4 times.

9. After the last round of selection, infect CV-1 cells in a well of a 6-well plate with 30-40 $\mu$ l plaque material. Incubate the cells until complete CPE develops (2-4 days). Harvest the cells and divide them into two Eppendorf tubes. One tube should be stored at $-20{ }^{\circ} \mathrm{C}$, which can be used later for further mutagenesis. Prepare vaccinia virus DNA from the other half of the reaction to verify the result of the recombination event by PCR.

The recovery of recombinant FCoVs comprises the generation of the full-length FCoV RNA by in vitro transcription and the introduction of this RNA into eukaryotic cells. In these cells, the 
3.3.1 In Vitro

Transcription (IVT) coronaviral life cycle is initiated and the newly produced recombinant viruses are released into the cell culture supernatant.

Vaccinia virus DNA, which contains the full-length FCoV genome is used as a template for the in vitro transcription.

1. Cells infected with the appropriate vaccinia virus are used for a large-scale DNA preparation as described above (section "Large-Scale Vaccinia Virus DNA Preparation").

2. Digest the entire amount of DNA with a unique cutter restriction enzyme (e.g., ClaI) for $3-4$ h at $37^{\circ} \mathrm{C}$. The digestion of the vaccinia virus DNA with this enzyme will enable the T7 polymerase driven RNA synthesis to terminate during the in vitro transcription.

3. Perform phenol-chloroform extraction of the digested DNA as described (section "Large-Scale Vaccinia Virus DNA Preparation", steps 14-18) and resuspend the DNA pellet in $25 \mu$ RNase-free water (see Note 2).

4. Used the entire DNA $(25 \mu \mathrm{l})$ for the in vitro transcription reaction using RiboMaxLarge Scale RNA Production System (Promega). The IVT reaction contains the following components in $50 \mu \mathrm{l}$ :

\begin{tabular}{ll}
\hline $3.8 \mu \mathrm{l}$ & ATP, CTP and UTP (100 mM each) \\
$0.7 \mu \mathrm{l}$ & GTP (100 mM) \\
$5 \mu \mathrm{l}$ & Cap Analog (30 mM m7GpppG) \\
$10 \mu \mathrm{l}$ & $5 \times$ transcription buffer \\
\hline $5 \mu \mathrm{l}$ & T7-Enzyme mix \\
\hline $0.5 \mu \mathrm{l}$ & RNase inhibitor \\
$25 \mu \mathrm{l}$ & ClaI cleaved vaccinia virus DNA \\
\hline
\end{tabular}

5. Incubate the IVT at $30{ }^{\circ} \mathrm{C}$ for $2-3 \mathrm{~h}$.

6. Add 2-4 $\mu \mathrm{l}$ RNase-free DNase to the reaction and incubate for $20 \mathrm{~min}$ at $37^{\circ} \mathrm{C}$.

7. Precipitate the RNA using $27 \mu \mathrm{LiCl}$ and incubate the reaction at $-20{ }^{\circ} \mathrm{C}$ for at least $30 \mathrm{~min}$.

8. Spin the reaction $\left(13,000 \mathrm{RPM}, 4^{\circ} \mathrm{C}, 20 \mathrm{~min}\right)$ in order to pellet the RNA.

9. Discard the supernatant and wash the pellet twice with $500 \mu \mathrm{l}$ $70 \%$ ethanol.

10. Resolve the pellet in $20 \mu \mathrm{l}$ RNase-free water and analyze $2 \mu \mathrm{l}$ of it on an agarose gel. This RNA can be stored at $-80{ }^{\circ} \mathrm{C}$ or directly used for the electroporation (Sect. 3.3.2). However, it is recommended to use the RNA immediately for the electroporation. 


\subsubsection{Electroporation of the RNA}

1. Use for the electroporation an inducible Crfk-Tet/On cell line, which expresses the FCoV N protein.

2 . Induce the cells in a $10 \mathrm{~cm}$ dish $20-24 \mathrm{~h}$ prior electroporation with doxycycline.

3 . Trypsinize the cells $20-24 \mathrm{~h}$ after induction, pellet (2000 $\mathrm{RPM}, 4{ }^{\circ} \mathrm{C}, 3 \mathrm{~min}$ ) and wash the cells twice with $10 \mathrm{ml}$ of ice cold PBS.

4. Count the cells, pellet again (2000 RPM, $\left.4{ }^{\circ} \mathrm{C}, 3 \mathrm{~min}\right)$ and resuspend the pellet in PBS to obtain $1 \times 10^{6}$ to $1 \times 10^{7}$ cells in $800 \mu \mathrm{l}$.

5. Transfer the $800 \mu \mathrm{l}$ into a $4 \mathrm{~mm}$ gap electroporation cuvette.

6. Add the FCoV RNA (Sect. 3.3.1) to the cells and mix gently.

7. Electroporate the RNA with one pulse using a Gene Pulser II (Bio-Rad) (Resistance: $\infty$, high-capacity: $950 \mu \mathrm{F}, 0.18 \mathrm{kV})($ see Note 7).

8. Transfer the cells into a $10 \mathrm{~cm}$ dish and fill up the dish with $10 \mathrm{ml}$ of fresh medium.

9. Optionally, change the medium 2-3 h after the electroporation.

10. Incubate the cells until CPE develops (usually 2-3 days). Harvest the supernatant containing the recombinant FCoVs and use it for further analysis.

\section{Notes}

1. Avoid the application of UV-light to excise the bands from the agarose gel. We experienced that exposing the DNA to UVlight can hamper the ligation of these fragments into the vaccinia virus genome. To assess the exact position of a DNA band without damaging it with UV-light, load DNA marker on both sides of your digested fragment on the agarose gel. After electrophoresis, separate the lanes with the marker from the remaining part (contains the digested fragments) of the gel. Using UV-light, cut out a small piece in each of the marker lanes at the expected height of the digested product. Position these lanes back together with the part containing the digested fragment. Cut the agarose gel between the two indicated positions in order to remove the agarose slice with the digested fragment.

2. Do not pipette vaccinia virus DNA with regular tips after proteinase $\mathrm{K}$ digestion. These tips can damage the DNA due to their narrow opening. Cut the end of the tips with scissors to enlarge the opening. 
3. In order to keep the DNA intact, do not vortex the tubes containing vaccinia virus DNA after proteinase $\mathrm{K}$ digestion. Vortexing can break the large vaccinia virus DNA.

4. Do not dry the vaccinia virus pellet but resuspend it immediately in water.

5. In our laboratory CHEF Mapper-II pulse-field gel electrophoresis System (Bio-Rad) is used. For the optimal separation of the bands a $1 \%$ agarose gel should be prepared. The gel runs for approximately $18 \mathrm{~h}$ (switch time 3-30 s, angle $120^{\circ}$, voltage $6 \mathrm{~V} / \mathrm{cm}$ ). The set up can vary depending on the system used for PFGE.

6. The vaccinia DNA itself is not infectious. The addition of fowlpox virus as a helper virus allows the rescue of recombinant vaccinia virus. Furthermore, the infection of CV-1 cells with the fowl-pox virus leads to an abortive infection. After the rescue of the recombinant vaccinia viruses there is no infectious fowl-pox virus present in the reaction.

7. The conditions for the electroporation depend on the cell line and device used for the electroporation. It is recommended to test a given electroporator with the cells to achieve optimal efficiency.

\section{References}

1. Tekes G, Hofmann-Lehmann R, Stallkamp I, Thiel V, Thiel HJ (2008) Genome organization and reverse genetic analysis of a type I feline coronavirus. J Virol 82(4):1851-1859. doi:10.1128/JVI.02339-07

2. Thiel V, Herold J, Schelle B, Siddell SG (2001) Infectious RNA transcribed in vitro from a cDNA copy of the human coronavirus genome cloned in vaccinia virus. J Gen Virol $82(\mathrm{Pt}$ 6):1273-1281

3. Casais R, Thiel V, Siddell SG, Cavanagh D, Britton P (2001) Reverse genetics system for the avian coronavirus infectious bronchitis virus. J Virol 75(24):12359-12369. doi:10.1128/JVI.75.24.12359-12369.2001

4. Coley SE, Lavi E, Sawicki SG, Fu L, Schelle B, Karl N, Siddell SG, Thiel V (2005) Recombinant mouse hepatitis virus strain A59 from cloned, full-length cDNA replicates to high titers in vitro and is fully pathogenic in vivo. J Virol 79(5):3097-3106. doi:10.1128/JVI.79.5.3097-3106.2005

5. Almazan F, Gonzalez JM, Penzes Z, Izeta A, Calvo E, Plana-Duran J, Enjuanes L (2000) Engineering the largest RNA virus genome as an infectious bacterial artificial chromosome. Proc Natl Acad Sci U S A 97(10):5516-5521
6. Balint A, Farsang A, Zadori Z, Hornyak A, Dencso L, Almazan F, Enjuanes L, Belak S (2012) Molecular characterization of feline infectious peritonitis virus strain DF-2 and studies of the role of ORF3abc in viral cell tropism. JVirol 86(11):6258-6267. doi:10.1128/ JVI.00189-12

7. Almazan F, Dediego ML, Galan C, Escors D, Alvarez E, Ortego J, Sola I, Zuniga S, Alonso S, Moreno JL, Nogales A, Capiscol C, Enjuanes L (2006) Construction of a severe acute respiratory syndrome coronavirus infectious cDNA clone and a replicon to study coronavirus RNA synthesis. J Virol 80(21):10900-10906. doi: 10.1128/JVI.00385-06

8. St-Jean JR, Desforges M, Almazan F, Jacomy $\mathrm{H}$, Enjuanes L, Talbot PJ (2006) Recovery of a neurovirulent human coronavirus OC43 from an infectious cDNA clone. J Virol 80(7):3670-3674.doi:10.1128/JVI.80.7.36703674.2006

9. Youn S, Leibowitz JL, Collisson EW (2005) In vitro assembled, recombinant infectious bronchitis viruses demonstrate that the $5 \mathrm{a}$ open reading frame is not essential for replication. Virology 332(1):206-215. doi:10.1016/j. virol.2004.10.045 
10. Yount B, Denison MR, Weiss SR, Baric RS (2002) Systematic assembly of a full-length infectious cDNA of mouse hepatitis virus strain A59. J Virol 76(21):11065-11078

11. Yount B, Curtis KM, Fritz EA, Hensley LE, Jahrling PB, Prentice E, Denison MR, Geisbert TW, Baric RS (2003) Reverse genetics with a full-length infectious cDNA of severe acute respiratory syndrome coronavirus. Proc Natl Acad Sci U S A 100(22):12995-13000. doi:10.1073/ pnas. 1735582100

12. Merchlinsky M, Moss B (1992) Introduction of foreign DNA into the vaccinia virus genome by in vitro ligation: recombination-independent selectable cloning vectors. Virology 190(1): 522-526

13. Hertzig T, Scandella E, Schelle B, Ziebuhr J, Siddell SG, Ludewig B, Thiel V (2004) Rapid identification of coronavirus replicase inhibitors using a selectable replicon RNA. J Gen Virol 85(Pt 6):1717-1725

14. Tekes G, Hofmann-Lehmann R, Bank-Wolf B, Maier R, Thiel HJ, Thiel V (2010) Chimeric feline coronaviruses that encode type II spike protein on type I genetic background display accelerated viral growth and altered receptor usage. J Virol 84(3):1326-1333. doi:10.1128/ JVI.01568-09

15. Tekes G, Spies D, Bank-Wolf B, Thiel V, Thiel HJ (2012) A reverse genetics approach to study feline infectious peritonitis. JVirol 86(12):69946998. doi:10.1128/JVI.00023-12

16. Thiel V, Thiel HJ, Tekes G (2014) Tackling feline infectious peritonitis via reverse genetics. Bioengineered 5(6):396-400. doi:10.4161/ bioe. 32133 